\title{
openheart Polypharmacy and health outcomes in atrial fibrillation: a systematic review and meta-analysis
}

\author{
Celine Gallagher, ${ }^{1}$ Karin Nyfort-Hansen, ${ }^{1}$ Debra Rowett, ${ }^{2}$ Christopher X Wong, ${ }^{1}$ \\ Melissa E Middeldorp, ${ }^{1}$ Rajiv Mahajan (1) , ${ }^{1}$ Dennis H Lau, ${ }^{1}$ Prashanthan Sanders, ${ }^{1}$ \\ Jeroen M Hendriks (D) ${ }^{1,3}$
}

\begin{abstract}
- Additional material is published online only. To view please visit the journal online (http://dx.doi.org/10.1136/ openhrt-2020-001257).
\end{abstract}

To cite: Gallagher $\mathrm{C}$, Nyfort-Hansen K, Rowett D, et al. Polypharmacy and health outcomes in atrial fibrillation: a systematic review and metaanalysis. Open Heart 2020;7:e001257. doi:10.1136/ openhrt-2020-001257

Received 31 January 2020 Revised 26 February 2020 Accepted 3 March 2020

Check for updates

C) Author(s) (or their employer(s)) 2020. Re-use permitted under CC BY-NC. No commercial re-use. See rights and permissions. Published by BMJ.

${ }^{1}$ Centre for Heart Rhythm Disorders, University of Adelaide and Royal Adelaide Hospital, Adelaide, South Australia, Australia

${ }^{2}$ School of Pharmacy and Medical Sciences, University of South Australia and Drug and Therapeutics Information Service, Southern Adelaide Local Health Network, Adelaide, South Australia, Australia

${ }^{3}$ College of Nursing and Health Sciences, Flinders University, Adelaide, South Australia, Australia

Correspondence to Dr Jeroen M Hendriks; jeroen. hendriks@adelaide.edu.au

\section{ABSTRACT}

Objective To undertake a systematic review and metaanalysis examining the impact of polypharmacy on health outcomes in atrial fibrillation (AF).

Data sources PubMed and Embase databases were searched from inception until 31 July 2019. Studies including post hoc analyses of prospective randomised controlled trials or observational design that examined the impact of polypharmacy on clinically significant outcomes in AF including mortality, hospitalisations, stroke, bleeding, falls and quality of life were eligible for inclusion.

Results A total of six studies were identified from the systematic review, with three studies reporting on common outcomes and used for a meta-analysis. The total study population from the three studies was 33602 and $37.2 \%$ were female. Moderate and severe polypharmacy, defined as 5-9 medicines and $>9$ medicines, was observed in $42.7 \%$ and $20.7 \%$ of patients respectively, and was associated with a significant increase in allcause mortality (Hazard ratio [HR] 1.36, 95\% Cl 1.20 to 1.54, $\mathrm{p}<0.001$; HR 1.84, $95 \% \mathrm{Cl} 1.40$ to $2.41, \mathrm{p}<0.001$, respectively), major bleeding ( $\mathrm{HR} 1.32,95 \% \mathrm{Cl} 1.14$ to 1.52, $\mathrm{p}<0.001$; HR $1.68,95 \% \mathrm{Cl} 1.35$ to $2.09, \mathrm{p}<0.001$, respectively) and clinically relevant non-major bleeding ( $\mathrm{HR} 1.12,95 \% \mathrm{Cl} 1.03$ to 1.22, $\mathrm{p}<0.01$; HR 1.48, 95\% Cl 1.33 to $1.64, p<0.01$, respectively). There was no statistically significant association between polypharmacy and stroke or systemic embolism or intracranial bleeding. Among other examined outcomes, polypharmacy was associated with cardiovascular death, hospitalisation, reduced quality of life and poorer physical function. Conclusions Polypharmacy is highly prevalent in the AF population and is associated with numerous adverse outcomes.

PROSPERO registration number CRD42018105298.

\section{INTRODUCTION}

In many countries ageing populations and rising numbers of concomitant cardiovascular risk factors are contributing to the increasing prevalence of atrial fibrillation (AF) and other chronic diseases. ${ }^{12}$ A Swedish registry study of 272186 patients with incident AF reported that $69.5 \%$ of patients had at least one of seven other long-term comorbid

\section{Key questions}

What is already known about this subject?

- Polypharmacy has been associated with numerous adverse outcomes in selected general populations, including mortality, falls, hospitalisations, reduced quality of life and economic burden.

- A synthesis of the literature examining health outcomes associated with polypharmacy in the atrial fibrillation (AF) population has not been undertaken.

What does this study add?

- Polypharmacy in patients with AF is independently associated with an increased risk of adverse outcomes including all-cause mortality, major bleeding, clinically relevant non-major bleeding, hospitalisations, reduced quality of life and poorer physical function.

How might this impact on clinical practice?

- Regular reconciliation and review of a patient's prescribed and non-prescribed medicines can help identify inappropriate polypharmacy and provide opportunities to minimise polypharmacy-associated harm.

conditions compared with $29.2 \%$ in matched controls. $^{3}$ A UK Biobank study of 3651 patients aged 40-70 years with self-reported $\mathrm{AF}$ also found the presence of at least one other self-reported long-term comorbidity in $80.4 \%$ of participants, compared with $65.3 \%$ of 498986 controls. ${ }^{4}$

Pharmacotherapy is a cornerstone in the management for $\mathrm{AF}$ and many of the comorbidities common in patients with $\mathrm{AF}$, such as hypertension, heart failure, coronary artery disease and diabetes. Diseasespecific treatment guidelines recommend the prescribing of medication for many patients, and combination therapy is common in those with moderate to severe disease. ${ }^{5-10}$ For patients with multimorbidity, the potential benefit of combining evidence-based therapies needs to be balanced with the 
risk of adverse health outcomes. Definitions of polypharmacy have varied in research studies, with the most common being the use of five or more medications, ${ }^{11}$ although there is evidence suggesting a continuum of risk. ${ }^{12}$ The challenge of adjusting for multimorbidity is well recognised. ${ }^{13}$ Many studies have focused on adverse outcomes in older patients over 65 years. These harms may include increased mortality, ${ }^{14-17}$ adverse drug reactions (ADR) and events, ${ }^{18} 19$ falls, ${ }^{14} 172021$ increased hospitalisations, ${ }^{14} 15172223$ lower quality of life, ${ }^{24} 25$ increased healthcare $\operatorname{costs}^{26}$ and medication burden on patients and carers. ${ }^{27}$

Comparatively little research has been done on the prevalence of polypharmacy in patients with $\mathrm{AF}$ and possible associated adverse health outcomes. Polypharmacy prevalence in $\mathrm{AF}$ has ranged from $40 \%$ to $95 \%$ depending on the setting, study population, ascertainment criteria and methods. ${ }^{28} 29$ Some medications commonly used by patients with $\mathrm{AF}$, including antihypertensive agents and anticoagulation agents, are leading causes of adverse drug events in the elderly. ${ }^{19}$ Many patients also take nonprescription or alternative medicines which carry their own potential for harm and interaction with prescribed medicines. ${ }^{30}$ In a cross-sectional study of chronic disease clusters in elderly hospitalised patients, AF with comorbid heart failure showed the third strongest association with polypharmacy. ${ }^{31}$ Post hoc analyses of two direct acting oral anticoagulant trials suggest that polypharmacy may be independently associated with adverse health outcomes. $^{32} 33$

As polypharmacy in AF may be an underappreciated risk factor for harm irrespective of anticoagulation status, we performed a systematic review and meta-analysis to summarise the best available evidence.

\section{METHODS}

\section{Literature search}

This systematic review was registered with PROSPERO and was undertaken in accordance with the Preferred Reporting Items for Systematic Reviews and MetaAnalyses guidelines. ${ }^{34}$ PubMed and Embase databases were independently searched by two authors (CG and $\mathrm{KNH}$ ) without date restriction until 31 July 2019. Keywords used included 'atrial fibrillation', 'polypharmacy', 'polypharmacology', 'pharmacoepidemiology', 'cardiovascular outcomes', 'health outcomes', 'cerebrovascular accident', 'bleeding', 'mortality', 'death', 'hospitalisation', 'hospital admission', 'quality of life', 'transient ischaemic attack' and 'falls'. See online supplementary eTable 1 for an outline of the full search strategy.

\section{Inclusion and exclusion criteria}

Studies were eligible for inclusion if they were prospective randomised controlled trials or of observational design, had a minimum follow-up of 3 months and were published in English. Outcomes eligible for inclusion included all-cause or cardiovascular mortality, all-cause or cardiovascular hospitalisations, stroke and systemic embolism, transient ischaemic attack, major bleeding (according to the International Society of Thrombosis and Haemostasis definition as bleeding associated with: reduction in haemoglobin of $20 \mathrm{~g} / \mathrm{L}$ over a 24-hour period, transfusion of two or more units of red cells, fatal bleeding or bleeding at a critical site; eg, retroperitoneal, pericardial),${ }^{35}$ non-major bleeding, intracranial bleeding, quality of life and falls. These outcomes were selected as they are either commonly studied in the AF population, or of significant clinical importance. Studies were excluded if they were of retrospective design, were not published in English or examined other health outcomes, economic costs or outcomes which were not directly health related, including drug interactions without clinical sequelae.

\section{Study selection and data extraction}

Two study investigators (CG and $\mathrm{KNH}$ ) independently reviewed all articles retrieved by the electronic search to determine eligible studies. Any discrepancies were discussed and resolved by consensus decision. Data extracted from relevant studies included: first author, year of publication, total number of participants, gender of included participants, mean age, follow-up period, AF ascertainment, polypharmacy definition, types of medicines collected from participants, endpoint adjudication and covariates adjusted for. The risk of bias in each of the included studies was assessed using the Quality in Prognosis Studies tool, ${ }^{36}$ and subjectively characterised as low, moderate or high.

\section{Statistical analysis}

The risk estimate for each outcome was independently extracted by two study investigators (CG and $\mathrm{KNH}$ ) according to two levels of polypharmacy (moderate and severe). The most adjusted model in each study was used. Heterogeneity across studies was assessed using the $\mathrm{I}^{2}$ statistic. Publication bias was assessed by visual inspection of funnel plots of effect size against standard error. A two-tailed $p$ value $<0.05$ was considered statistically significant. All analyses were performed using a random effects model in Review Manager (RevMan) V.5.3, Copenhagen: The Nordic Cochrane Centre, The Cochrane Collection, 2014.

\section{Patient and public involvement}

Due to the nature of this research it was undertaken without patient or public involvement. Patients were not invited to comment on the study design or patientrelevant outcomes or to assist with interpretation of the results. Patients did not contribute to the writing or editing of this document for readability or accuracy.

\section{RESULTS}

A total of 791 articles were identified from the electronic search, with 65 retrieved for full-text review. Of these, 59 did not meet the inclusion criteria, with the remaining six studies eligible (figure 1). This includes 


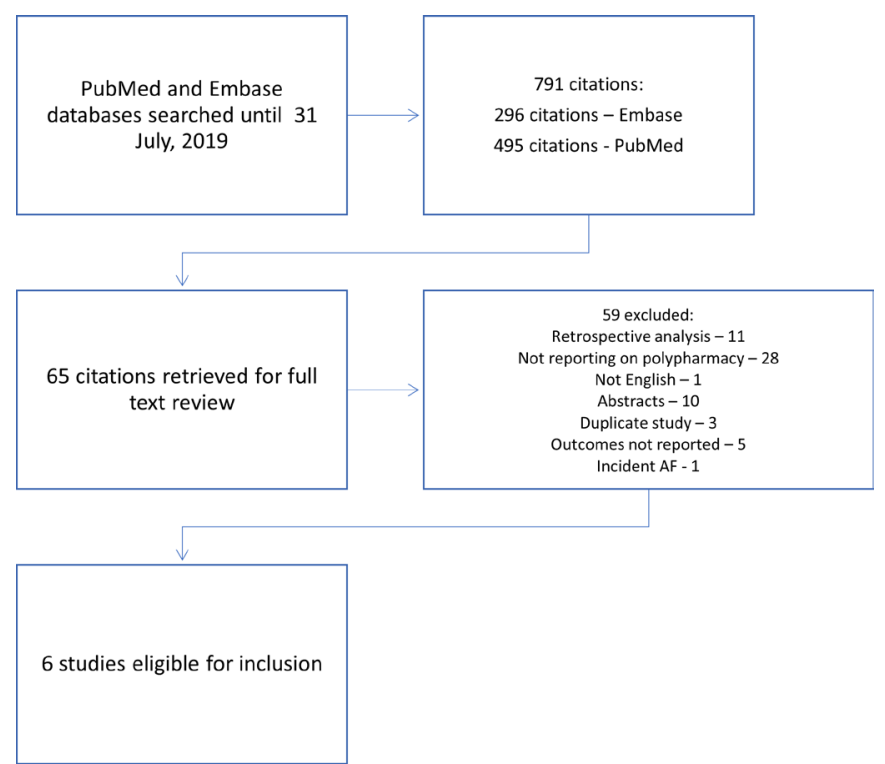

Figure 1 Flow chart of study. AF, atrial fibrillation.

one study examining the impact of polypharmacy on clinical outcomes in an anticoagulated population in which $73 \%$ of the study population had AF. ${ }^{37}$ The authors of this study were contacted and provided outcomes specific to the AF subpopulation of this study. The prevalence of polypharmacy ranged from $40.1 \%$ ( $\geq 5$ cardiovascular medicines) to $78.8 \%$ ( $\geq 5$ overall medicines). ${ }^{28}{ }^{37}$ More than one of the included studies reported on common outcomes including all-cause mortality, stroke or systemic embolism, major bleeding, intracranial bleeding and clinically relevant non-major bleeding and were able to be used for a meta-analysis, ${ }^{32} 3337$ with the three remaining studies examining other outcomes including cardiovascular mortality ${ }^{28}$ and quality of life. ${ }^{38}{ }^{39}$ Due to heterogeneous reporting of quality of life, a meta-analysis of this outcome was unable to be performed. See table 1 for characteristics of the included studies. The total study population of the meta-analysis was 33602 individuals of which $37.2 \%$ were female. In the three studies included in the meta-analysis, risk of bias was assessed as low in two studies, ${ }^{33} 37$ and moderate in the other (online supplementary eTable 2). ${ }^{32}$

\section{Polypharmacy definition}

There was slight variation in the definition of polypharmacy used across the three studies included in the metaanalysis. For the purpose of this study we have classified moderate polypharmacy as the group of five to nine medications in one study, ${ }^{33}$ six to eight in the second study ${ }^{32}$ and five to eight in the third study. ${ }^{37}$ Severe polypharmacy was classified as $\geq 10$ in one study and $\geq 9$ medicines in two studies. The reference group was zero to four medicines in two studies ${ }^{3337}$ and zero to five medicines in

Table 1 Characteristics of studies included in the meta-analysis

\begin{tabular}{|c|c|c|c|c|c|c|c|c|}
\hline Study & $\begin{array}{l}\text { Year of } \\
\text { publication }\end{array}$ & $\begin{array}{l}\text { Participants, } \\
\text { n }\end{array}$ & $\begin{array}{l}\text { Median } \\
\text { age }\end{array}$ & $\begin{array}{l}\% \\
\text { female }\end{array}$ & $\begin{array}{l}\text { Reported } \\
\text { medication } \\
\text { categories }\end{array}$ & $\begin{array}{l}\text { Median } \\
\text { duration } \\
\text { follow-up } \\
\text { (years) }\end{array}$ & Outcome measures & $\begin{array}{l}\text { Covariates adjusted } \\
\text { for }\end{array}$ \\
\hline $\begin{array}{l}\text { Rivaroxaban } \\
\text { versus Warfarin } \\
\text { in Nonvalvular } \\
\text { Atrial } \\
\text { Fibrillation } \\
\text { (ROCKET-AF) }^{33}\end{array}$ & 2016 & 14264 & 73 & 39.7 & $\begin{array}{c}\text { Reference group: } \\
0-4,5-9, \geq 10 \\
\text { medicines }\end{array}$ & 1.9 & $\begin{array}{l}\text { All-cause mortality, stroke, non- } \\
\text { CNS embolism, vascular death, } \\
\text { MI, intracranial bleeding, major } \\
\text { bleeding, non-major clinically } \\
\text { relevant bleeding }\end{array}$ & $\begin{array}{l}\text { Age, sex, BMI, region, } \\
\text { DM, previous stroke/TIA, } \\
\text { vascular disease, CHF, } \\
\text { hypertension, COPD, PAF, } \\
\text { DBP, creatinine clearance } \\
\text { (Cockcroft-Gault), heart } \\
\text { rate, alcohol use and } \\
\text { randomised treatment* }\end{array}$ \\
\hline $\begin{array}{l}\text { Apixaban } \\
\text { versus Warfarin } \\
\text { in Patients } \\
\text { with Atrial } \\
\text { Fibrillation } \\
\text { (ARISTOTLE) }^{32}\end{array}$ & 2016 & 18201 & 70 & 35.3 & $\begin{array}{c}\text { Reference group: } \\
0-5,6-8, \geq 9 \\
\text { medicines }\end{array}$ & 1.8 & $\begin{array}{l}\text { Stroke, systemic embolism, } \\
\text { all-cause mortality, major } \\
\text { bleeding, intracranial bleeding, } \\
\text { Gl bleeding, clinically relevant } \\
\text { non-major bleeding }\end{array}$ & Age, sex, country \\
\hline $\begin{array}{l}\text { Evaluation } \\
\text { of Oral } \\
\text { Anticoagulation } \\
\text { with Vitamin } \\
\text { K Antagnoists } \\
\text { - the } \\
\text { thrombEVAL } \\
\text { Study } \\
\text { Programme } \\
\text { (thrombEVAL) }^{37}\end{array}$ & 2019 & 1137 & 74 & 36.8 & $\begin{array}{c}\text { Reference group: } \\
0-4,5-8, \geq 9 \\
\text { medicines }\end{array}$ & 2.3 & $\begin{array}{l}\text { All-cause mortality, } \\
\text { hospitalisation, stroke, TIA, } \\
\text { major bleeding, clinically } \\
\text { relevant non-major bleeding, } \\
\text { intracranial bleeding }\end{array}$ & $\begin{array}{l}\text { Age, sex, diabetes, } \\
\text { dyslipidaemia, } \\
\text { hypertension, obesity, } \\
\text { family history of MI, } \\
\text { current smoking and } \\
\text { Charlson Comorbidity } \\
\text { Index }\end{array}$ \\
\hline
\end{tabular}

*Safety endpoints adjusted for age, sex, region, previous stroke/TIA, anaemia, previous GI bleed, COPD, DBP, creatinine clearance (Cockroft-Gault), platelets, albumin, previous aspirin, vitamin $\mathrm{K}$ antagonist, thienopyridine and randomised treatment.

BMI, body mass index; CHF, congestive heart failure; CNS, central nervous system; COPD, chronic obstructive pulmonary disease; DBP, diastolic blood pressure; DM, diabetes mellitus; GI, gastrointestinal; MI, myocardial infarction; PAF, paroxysmal atrial fibrillation; TIA, transient ischaemic attack. 
A

\begin{tabular}{|c|c|c|c|c|c|c|c|c|c|c|}
\hline \multirow[b]{2}{*}{ Study or Subgroup } & \multirow[b]{2}{*}{ log[Hazard Ratio] } & \multicolumn{4}{|c|}{ Moderate polypharmacy Reference } & \multirow{2}{*}{$\begin{array}{c}\text { Hazard Ratio } \\
\text { N, Random, 95\% Cl }\end{array}$} & \multirow{2}{*}{\multicolumn{4}{|c|}{$\begin{array}{c}\text { Hazard Ratio } \\
\mathrm{N}, \text { Random, } 95 \% \mathrm{Cl}\end{array}$}} \\
\hline & & SE & Total & Total & Weight & & & & & \\
\hline Eggebrecht 2019 & 0.5306 & 0.1906 & 557 & 241 & $10.2 \%$ & $1.70[1.17,2.47]$ & & & & \\
\hline Focks 2016 & 0.3436 & 0.0697 & 6502 & 6943 & $45.0 \%$ & $1.41[1.23,1.62]$ & & & - & \\
\hline Piccini 2016 & 0.2231 & 0.0699 & 7251 & 5058 & $44.8 \%$ & $1.25[1.09,1.43]$ & & & - & \\
\hline Total $(95 \% \mathrm{Cl})$ & & & 14310 & 12242 & $100.0 \%$ & $1.36[1.20,1.54]$ & & & & \\
\hline \multicolumn{3}{|c|}{$\begin{array}{l}\text { Heterogeneity: } \text { Tau }^{2}=0.00 ; C h i^{2}=3.06, d f=2(P=0.22) ; I^{2}=35 \% \\
\text { Test for overall effect: } Z=4.79(P<0.00001)\end{array}$} & & & & & 0.2 & $\begin{array}{l}0.5 \\
\text { Lower risk }\end{array}$ & $\begin{array}{rr} & 1 \\
\text { Higher risk }\end{array}$ & 5 \\
\hline
\end{tabular}

B

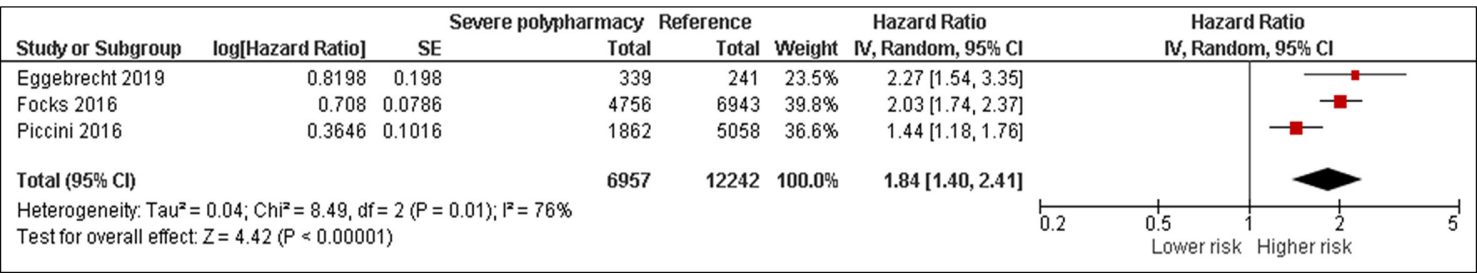

Figure 2 Impact of moderate (A) and severe (B) polypharmacy on all-cause mortality.

the other. ${ }^{32}$ See table 1 for an outline of studies eligible for inclusion.

\section{All-cause mortality}

Both moderate and severe polypharmacy was associated with significant increases in all-cause mortality (HR 1.36, $95 \%$ CI 1.20 to $1.54, \mathrm{p}<0.001$; HR $1.84,95 \%$ CI 1.40 to $2.41, \mathrm{p}<0.001$, respectively; see figure 2 ). There was no evidence of statistical heterogeneity with moderate polypharmacy $\left(\mathrm{I}^{2}=35 \%, \mathrm{p}=0.22\right)$, however, there was evidence of heterogeneity with severe polypharmacy $\left(\mathrm{I}^{2}=76 \%\right.$, $\mathrm{p}=0.01$ ).

\section{Stroke or systemic embolism}

Neither moderate nor severe polypharmacy was associated with stroke or systemic embolism (HR 1.09, 95\% CI 0.83 to 1.43 , $\mathrm{p}=0.56$; HR $1.17,95 \%$ CI 0.79 to $1.74, \mathrm{p}=0.44$, respectively; figure 3). Moderate polypharmacy did not demonstrate any evidence of statistical heterogeneity with this outcome $\left(\mathrm{I}^{2}=61 \%, \mathrm{p}=0.08\right)$, with heterogeneity evident at the severe polypharmacy level $\left(\mathrm{I}^{2}=66 \%\right.$, $\mathrm{p}=0.05)$.

\section{Major bleeding}

Major bleeding was significantly increased with both moderate and severe polypharmacy (HR 1.32, 95\% CI 1.14 to $1.52, \mathrm{p}<0.001$; HR $1.68,95 \%$ CI 1.35 to 2.09 , $\mathrm{p}<0.001$, respectively; figure 4 ). There was no evidence of statistical heterogeneity with either moderate or severe polypharmacy $\left(\mathrm{I}^{2}=21 \%, \mathrm{p}=0.28 ; \mathrm{I}^{2}=47 \%, \mathrm{p}=0.15\right.$, respectively).

\section{Intracranial bleeding}

There was no impact of moderate or severe polypharmacy on intracranial bleeding (HR 1.37, 95\% CI 0.85 to $2.19, \mathrm{p}=0.19$; HR $1.37,95 \%$ CI 0.96 to $1.96, \mathrm{p}=0.08$, respectively; see figure 5). There was no evidence of statistical heterogeneity at the moderate polypharmacy level $\left(\mathrm{I}^{2}=53 \%, \mathrm{p}=0.12\right)$, nor severe polypharmacy with this outcome $\left(\mathrm{I}^{2}=12 \%, \mathrm{p}=0.32\right)$.

\section{Clinically relevant non-major bleeding}

Both moderate and severe polypharmacy was associated with an increased risk of clinically relevant non-major

A

\begin{tabular}{|c|c|c|c|c|c|c|c|c|c|}
\hline \multirow[b]{2}{*}{ Study or Subgroup } & \multirow[b]{2}{*}{ log[Hazard Ratio] } & \multicolumn{4}{|c|}{ Moderate polypharmacy Reference } & \multirow{2}{*}{$\begin{array}{l}\text { Hazard Ratio } \\
\text { N, Random, 95\% } \mathrm{Cl}\end{array}$} & \multirow{2}{*}{\multicolumn{3}{|c|}{$\begin{array}{c}\text { Hazard Ratio } \\
\text { N, Random, 95\% Cl }\end{array}$}} \\
\hline & & SE & Total & Total & Weight & & & & \\
\hline Eggebrecht 2019 & -0.844 & 0.5044 & 557 & 241 & $6.8 \%$ & $0.43[0.16,1.16]$ & $\leftarrow$ & & \\
\hline Focks 2016 & 0.239 & 0.1118 & 6502 & 6943 & $44.6 \%$ & $1.27[1.02,1.58]$ & & & \\
\hline Piccini 2016 & 0.0677 & 0.094 & 7251 & 5058 & $48.6 \%$ & $1.07[0.89,1.29]$ & & & \\
\hline \multicolumn{3}{|l|}{ Total $(95 \% \mathrm{Cl})$} & 14310 & 12242 & $100.0 \%$ & $1.09[0.83,1.43]$ & & & \\
\hline \multicolumn{3}{|c|}{$\begin{array}{l}\text { Heterogeneity: } \text { Tau }^{2}=0.03 ; \mathrm{Chi}^{2}=5.09, \mathrm{df}=2(P=0.08) ;\left.\right|^{2}=61 \% \\
\text { Test for overall effect: } Z=0.59(P=0.56)\end{array}$} & & & & & 0.2 & $\begin{array}{ccc}0.5 & 1 & 2 \\
\text { Lower risk } & \text { Higher risk }\end{array}$ & 5 \\
\hline
\end{tabular}

B

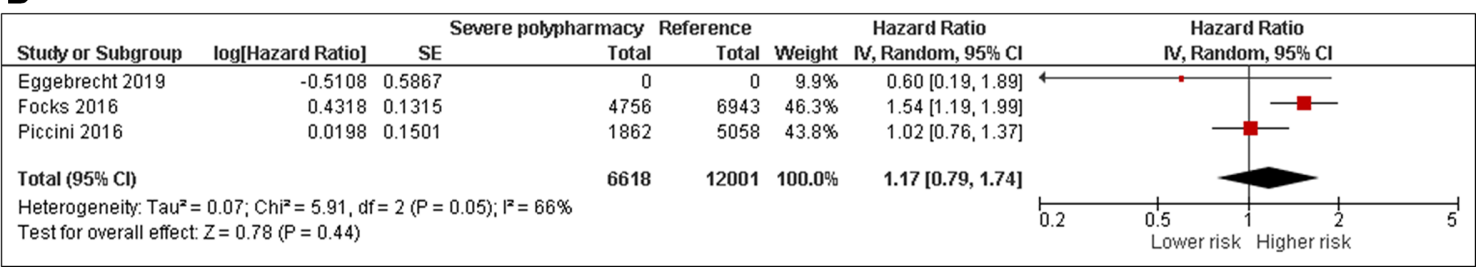

Figure 3 Impact of moderate (A) and severe (B) polypharmacy on stroke or systemic embolism. 


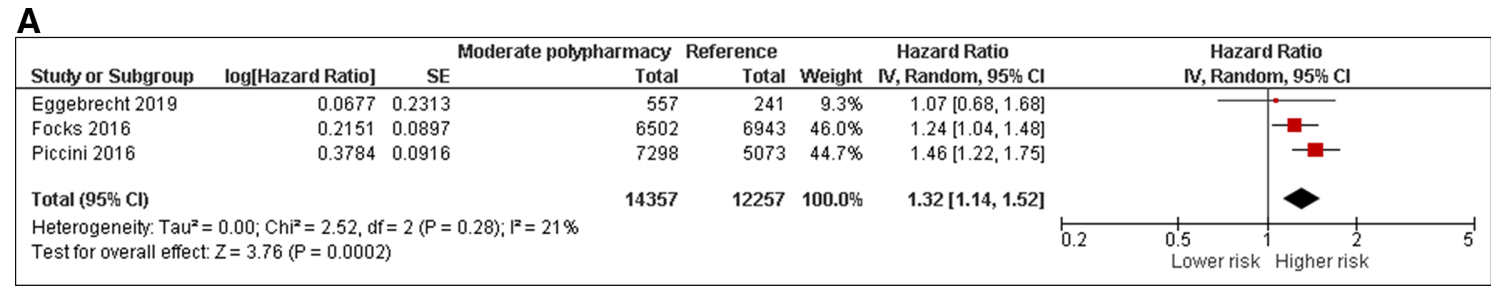

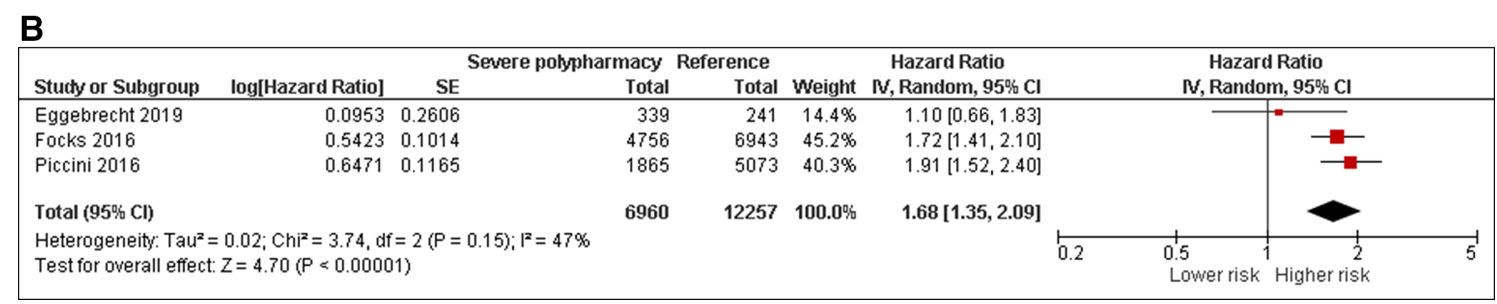

Figure 4 Impact of moderate (A) and severe (B) polypharmacy on major bleeding.

bleeding based on two studies reporting on this outcome (HR 1.12, 95\% CI 1.03 to $1.22, \mathrm{p}=0.009$; HR $1.48,95 \%$ CI 1.33 to $1.64, \mathrm{p}<0.001$, respectively; see figure 6 ). Neither moderate nor severe polypharmacy demonstrated any evidence of statistical heterogeneity for this outcome $\left(I^{2}=0 \%, p=0.49 ; I^{2}=0 \%, p=0.39\right.$, respectively $)$.

\section{Cardiovascular death}

Post hoc analysis of the Atrial Fibrillation Follow-up Investigation of Rhythm Management study, which examined the impact of polypharmacy of cardiovascular medicines only (defined as $>5$ medicines), demonstrated an increase in the risk of cardiovascular death (unadjusted HR 1.47, 95\% CI 1.18 to $1.82, \mathrm{p}<0.001$ ) and stroke (unadjusted HR $1.17,95 \%$ CI 0.85 to $1.60, \mathrm{p}=0.34) .{ }^{28}$ The adjusted relative risk for cardiovascular death was 1.30 (95\% CI 1.03 to 1.64, $\mathrm{p}=0.03$ ).

\section{Hospitalisation}

One study examined the impact of polypharmacy on all-cause hospitalisations. In this study of 1137 participants with AF from the Evaluation of Oral Anticoagulation with Vitamin K Antagonists - the thrombEVAL study programme (thrombEVAL) cohort, which assessed outcomes in individuals taking anticoagulant therapy, an adjusted increased risk was observed with both moderate (HR 1.23, 95\% CI 1.00 to $1.51 ; \mathrm{p}=0.051$ ) and severe (HR $1.32 ; 95 \%$ CI 1.05 to $1.68 ; \mathrm{p}=0.02$ ) polypharmacy. ${ }^{370}$

\section{Quality of life}

Two studies examined the impact of polypharmacy on quality of life. Post hoc analysis of the Birmingham Atrial Fibrillation Treatment of the Aged (BAFTA) study, which examined quality of life in 1762 elderly individuals $(>75$ years) with $\mathrm{AF}$, demonstrated that $>7$ medicines were associated with a significant reduction in quality of life as assessed by the EuroQol-5 Dimension (parameter estimate $-0.06, \mathrm{p}=0.03) .{ }^{38}$ There was no impact at other polypharmacy levels (1-3 or 4-6 medicines). Both moderate and severe polypharmacy was associated with a significant reduction in the physical component summary score of the 12-Item Short Form Health Survey (SF-12) ( $\mathrm{p}=0.03$ and $\mathrm{p}<0.0001$, respectively), but not the mental component summary score. Similarly, in another study of 662 community-dwelling adults ( $>65$ years) with AF, an unadjusted incremental decline in physical function assessed by self-reported ability to undertake five activities

A

\begin{tabular}{|c|c|c|c|c|c|c|c|c|c|c|}
\hline \multirow[b]{2}{*}{ Study or Subgroup } & \multirow[b]{2}{*}{ log[Hazard Ratio] } & \multicolumn{4}{|c|}{ Moderate polypharmacy Reference } & \multirow{2}{*}{$\begin{array}{c}\text { Hazard Ratio } \\
\mathrm{N}, \text { Random, } 95 \% \mathrm{Cl}\end{array}$} & \multirow{2}{*}{\multicolumn{4}{|c|}{$\begin{array}{c}\text { Hazard Ratio } \\
\text { N, Random, } 95 \% \mathrm{Cl}\end{array}$}} \\
\hline & & SE & Total & Total & Weight & & & & & \\
\hline Eggebrecht 2019 & 0.3716 & 0.8039 & $55 ?$ & 241 & $7.9 \%$ & $1.45[0.30,7.01]$ & & & & \\
\hline Focks 2016 & 0.0296 & 0.1827 & 6502 & 6943 & $48.7 \%$ & $1.03[0.72,1.47]$ & & & & \\
\hline Piccini 2016 & 0.6206 & 0.2194 & 7298 & 5073 & $43.4 \%$ & $1.86[1.21,2.86]$ & & & & \\
\hline Total $(95 \% \mathrm{Cl})$ & & & 14357 & 12257 & $100.0 \%$ & $1.37[0.85,2.19]$ & & & & \\
\hline $\begin{array}{l}\text { Heterogeneity: Tauz } \\
\text { Test for overall effect }\end{array}$ & $\begin{array}{l}0.09 ; C^{2} i^{2}=4.30, d \\
Z=1.30(P=0.19)\end{array}$ & $=2(P=0.12) ;\left.\right|^{2}=53 \%$ & & & & & 0.2 & Lower risk & Higher risk & 5 \\
\hline
\end{tabular}

B

\begin{tabular}{|c|c|c|c|c|c|c|c|c|c|c|}
\hline \multirow[b]{2}{*}{ Study or Subgroup } & \multirow[b]{2}{*}{ log[Hazard Ratio] } & \multicolumn{4}{|c|}{ Severe polypharmacy Reference } & \multirow{2}{*}{$\begin{array}{c}\text { Hazard Ratio } \\
\text { N, Random, } 95 \% \mathrm{Cl}\end{array}$} & \multirow{2}{*}{\multicolumn{4}{|c|}{$\begin{array}{c}\text { Hazard Ratio } \\
\text { N, Random, } 95 \% \mathrm{Cl}\end{array}$}} \\
\hline & & SE & Total & Total & Weight & & & & & \\
\hline Eggebrecht 2019 & 0.7031 & 0.866 & 339 & 241 & $4.3 \%$ & $2.02[0.37,11.03]$ & & & & \\
\hline Focks 2016 & 0.1398 & 0.1852 & 4756 & 6943 & $66.0 \%$ & $1.15[0.80,1.65]$ & & & & \\
\hline Piccini 2016 & 0.6523 & 0.3079 & 1865 & 5073 & $29.7 \%$ & $1.92[1.05,3.51]$ & & & & \\
\hline Total $(95 \% \mathrm{Cl})$ & & & 6960 & 12257 & $100.0 \%$ & $1.37[0.96,1.96]$ & & & & \\
\hline $\begin{array}{l}\text { Heterogeneity: Tau }{ }^{2} \\
\text { Test for overall effec }\end{array}$ & $\begin{array}{l}0.02 ; \mathrm{Chi}^{2}=2.27, \mathrm{df} \\
Z=1.75(\mathrm{P}=0.08)\end{array}$ & $=2(P=0.32) ; I^{2}=12 \%$ & & & & & 0.2 & $\begin{array}{l}0.5 \\
\text { Lower risk }\end{array}$ & $1 \frac{2}{1}{ }^{1}$ Higher risk & 5 \\
\hline
\end{tabular}

Figure 5 Impact of $(\mathrm{A})$ moderate and (B) severe polypharmacy on intracranial bleeding. 
A

\begin{tabular}{|c|c|c|c|c|c|c|c|c|c|c|}
\hline \multirow[b]{2}{*}{ Stucty or Subgroup } & \multirow[b]{2}{*}{ log[Hazard Ratio] } & \multicolumn{3}{|c|}{ Moderate polypharmacy Reference } & \multirow[b]{2}{*}{ Weight } & \multirow{2}{*}{$\begin{array}{c}\text { Hazard Ratio } \\
\mathrm{N}, \text { Random, } 95 \% \mathrm{Cl}\end{array}$} & \multirow{2}{*}{\multicolumn{4}{|c|}{$\begin{array}{c}\text { Hazard Ratio } \\
\text { N, Random, } 95 \% \mathrm{Cl}\end{array}$}} \\
\hline & & SE & Total & Total & & & & & & \\
\hline Focks 2016 & 0.1655 & 0.0896 & 6502 & 6943 & $22.7 \%$ & $1.18[0.99,1.41]$ & & & 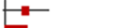 & \\
\hline Piccini 2016 & 0.0953 & 0.0486 & 7298 & 5073 & $77.3 \%$ & $1.10[1.00,1.21]$ & & & & \\
\hline Total $(95 \% \mathrm{Cl})$ & & & 13800 & 12016 & $100.0 \%$ & $1.12[1.03,1.22]$ & & & $>$ & \\
\hline $\begin{array}{l}\text { Heterogeneity: Tau } \\
\text { Test for overall effect }\end{array}$ & $\begin{array}{l}0.00 ; C^{2}=0.47, d f \\
Z=2.60(P=0.009)\end{array}$ & $=1(P=0.49) ; I^{2}=0 \%$ & & & & & 0.2 & $\begin{array}{l}0.5 \\
\text { Lower risk }\end{array}$ & $\begin{array}{cc}1 & 2 \\
\text { Higher risk }\end{array}$ & 5 \\
\hline
\end{tabular}

B

\begin{tabular}{|c|c|c|c|c|c|c|c|c|c|c|}
\hline Study or Subgroup & log[Hazard Ratio] & \multicolumn{4}{|c|}{ Severe polypharmacy Reference } & $\begin{array}{c}\text { Hazard Ratio } \\
\text { N, Random, 95\% Cl }\end{array}$ & \multicolumn{4}{|c|}{$\begin{array}{c}\text { Hazard Ratio } \\
\text { N, Random, } 95 \% \mathrm{Cl}\end{array}$} \\
\hline Focks 2016 & 0.4511 & 0.0885 & 4756 & 6943 & $34.8 \%$ & $1.57[1.32,1.87]$ & & & $\rightarrow-$ & \\
\hline Piccini 2016 & 0.3577 & 0.0646 & 1865 & 5073 & $65.2 \%$ & $1.43[1.26,1.62]$ & & & & \\
\hline Total (95\% Cl) & & & 6621 & 12016 & $100.0 \%$ & $1.48[1.33,1.64]$ & & & & \\
\hline $\begin{array}{l}\text { Heterogeneity: Tau } \\
\text { Test for overall effect }\end{array}$ & $\begin{array}{l}0.00 ; C_{h i}^{2}=0.73, d f \\
Z=7.48(P<0.0000\end{array}$ & $\begin{array}{l}=1(P=0.39) ; I^{2}=0 \% \\
\text { 1) }\end{array}$ & & & & & 0.2 & $\begin{array}{l}0.5 \\
\text { Lower risk }\end{array}$ & $\begin{array}{r}2 \\
2 \\
\text { Higher risk }\end{array}$ & 5 \\
\hline
\end{tabular}

Figure 6 Impact of moderate (A) and severe (B) polypharmacy on clinically relevant non-major bleeding.

was observed with both low ( $<7$ medications) and high $\left(\geq 7\right.$ medications) polypharmacy, respectively. ${ }^{39}$

\section{DISCUSSION}

Our systematic review and meta-analysis demonstrates the following in the AF population:

1. Moderate and severe polypharmacy is associated with a $36 \%$ and $84 \%$ increase in all-cause mortality, respectively.

2. The risk of major bleeding is increased by $32 \%$ and $68 \%$ for moderate and severe polypharmacy, respectively.

3. Clinically relevant non-major bleeding increased by $12 \%$ and $48 \%$, respectively, with moderate and severe polypharmacy.

4. No association was found between any level of polypharmacy and stroke or systemic embolism, or intracranial bleeding.

5. Polypharmacy is associated with an increased risk of cardiovascular death, hospitalisation, reduced quality of life and poorer physical functioning.

To date, there has been a paucity of studies examining the impact of polypharmacy on health outcomes in patients with AF, and few have used outcome data from prospective studies with independent endpoint adjudication as in the present meta-analysis. Given the increasing prevalence of concomitant risk factors in patients with $\mathrm{AF}^{13}{ }^{3}$ it is likely that, similar to other chronic diseases, the use of multiple medicines is driven by comorbid conditions. ${ }^{41} 42$ Adjustment for comorbidities is a challenge in polypharmacy research and although the studies in our meta-analysis varied in this regard, two of the three included studies adjusted for common confounding factors with significant HRs found in all outcomes with the exception of stroke or systemic embolism and intracranial bleeding.

The mechanisms underlying the adverse outcomes associated with polypharmacy are likely to be multifactorial and may vary between outcomes. Although polypharmacy is a marker for multimorbidity which contributes to poorer outcomes, potentially causal mechanisms that polypharmacy adds could include (1) reduced adherence and persistence to prescribed regimens; (2) drug-drug and drug-disease interactions; and (3) ADRs.

Adherence and persistence to prescribed regimens has been inversely correlated with number of medicines used. ${ }^{43} \mathrm{In}$ the heart failure population the number of drug-related negative outcomes, including inadequately treated health issues, inadequate doses or duration of treatment and non-adherence, has demonstrated a significant correlation with increasing number of medicines prescribed. ${ }^{44}$ In one of the studies included in our meta-analysis $42.4 \%$ of patients taking $\geq 10$ medications discontinued their anticoagulant, compared with $35.4 \%$ taking 5-9 medications and $31.8 \%$ taking $0-4$ medications. ${ }^{33}$ Polypharmacy may similarly have affected persistence with other medications. Non-adherence to dabigatran in patients with AF, defined as less than $20 \%$ adherence, has been shown to be associated with an increase in all-cause mortality and stroke in an observational registry (HR 1.54; 95\% CI 1.20 to $1.97 ; \mathrm{p}<0.01){ }^{45}$

Drug-drug and drug-disease interactions may be a contributing factor to polypharmacy-associated harm. It is possible that the observed increase in bleeding risk may reflect an increased likelihood of combining certain highrisk medications with anticoagulants. ${ }^{46}$ Many commonly used agents have potential interactions with anticoagulants including non-steroidal anti-inflammatory drugs (NSAIDs), antiplatelet agents or others with antiplatelet effects including selective serotonin reuptake inhibitors. Post hoc analyses of the Dabigatran versus Warfarin in Patients with Atrial Fibrillation (RE-LY) studydemonstrated that use of NSAIDs was associated with an increased risk of major bleeding, stroke or systemic embolism and all-cause hospitalisations. ${ }^{47}$ In the Apixaban versus Warfarin in Patients with Atrial Fibrillation (ARISTOTLE) post hoc analysis, aspirin, NSAIDs or prednisone was used by $13.8 \%$ in those taking $0-5$ medications, $31.7 \%$ taking $6-8$ and $49.7 \%$ taking $\geq 9$ medications. The risk of drug-drug interactions increases with growing numbers of medicines prescribed, with the risk identified to be as high as $82 \%$ in individuals prescribed seven or more 
medicines. ${ }^{48}$ Many of these interactions may be underrecognised by clinicians and possibly result in further use of medicines to treat ADRs. Compounding this situation, current guidelines are often single disease focused, with little advice for clinicians concerning management of the comorbid individual, and the potential for interactions with drug therapy for other conditions. ${ }^{49}$ The use of overthe-counter medicines is also under-recognised, with the risk of potentially unknown adverse interactions. A study of 250 individuals attending an anticoagulation clinic in Denmark demonstrated that almost $50 \%$ of individuals were taking alternative medicines including fish oil, and some with potential for interactions with warfarin. ${ }^{50}$ More research is needed to investigate whether adverse bleeding outcomes in patients with AF using polypharmacy are associated with certain drug-disease interactions or combinations of pharmacotherapy.

ADRs are associated with significant morbidity and mortality and in older patients ( $>65$ years of age) may account for 1 in 10 hospitalisations. ${ }^{19}$ As more medicines are taken the risk of ADRs increases. Anticoagulants and cardiovascular agents, commonly used in the AF population, are associated with bleeding and falls which may contribute to increased all-cause mortality either as a direct effect or secondary to discontinuation of therapy.

Our systematic review identified two studies in community-dwelling older adults examining the impact of polypharmacy on quality of life. A secondary analysis of the BAFTA study demonstrated that gender, number of prescribed medications and disability were all independently associated with quality of life. Poorer quality of life was observed in individuals taking greater than three medications, with greater impairment demonstrated in those taking more than seven medications. ${ }^{38}$ The other study identified in our systematic review also describes poorer physical functioning, based on an individual's ability to undertake five predetermined activities, with incremental declines observed for moderate and severe polypharmacy. ${ }^{39}$ This is consistent with Australian data which demonstrated an incremental association between poorer physical functioning, as determined by the SF-36, with moderate and severe polypharmacy, respectively. ${ }^{29}$ Together, these studies provide a strong signal of the association between poorer physical functioning and polypharmacy.

One study from our systematic review described an association between polypharmacy and all-cause hospitalisations. A longitudinal study has shown an increase in age, multimorbidity and polypharmacy in patients with heart failure over the years $1998-2008 .^{42}$ The question of whether a similar trend may be contributing to observed increases in AF hospitalisations deserves further investigation. $^{51}{ }^{52}$ Our systematic review did not identify any prospective studies examining the relationship between polypharmacy and falls in the AF population. Many studies in older patient populations have found polypharmacy to be associated with falls, and an unadjusted association was found in a small retrospective study of patients with $\mathrm{AF}$ with a mean age of 82 years $(\mathrm{p}=0.027) .{ }^{53}$ Other data have demonstrated an independent association between $\mathrm{AF}$ and hip fracture, ${ }^{54}$ and raise the possibility that polypharmacy may be a contributing factor to this observation. In the ARISTOTLE study, $8.8 \%$ of patients with severe polypharmacy had a history of falls during the year prior to enrolment, compared with $2.3 \%$ in those taking zero to five medications $(\mathrm{p}<0.001) .{ }^{32}$ A separate post hoc analysis of the ARISTOTLE study found that patients with a history of falls had an increased adjusted risk of major bleeding and all-cause mortality, and a more than threefold increased risk of falling during the trial. ${ }^{55}$ Larger prospective studies are needed to determine the mechanisms contributing to falls in patients with $\mathrm{AF}$ and the possible role of polypharmacy-associated decline in physical function.

Deprescribing has been defined as 'the process of withdrawal of an inappropriate medication, supervised by a health care professional with the goal of managing polypharmacy and improving outcomes' ${ }^{56}$ We are, however, unaware of any studies reporting on deprescribing outcomes specific to patients with AF. Current AF treatment guidelines recommend avoidance of certain medications depending on the clinical context, for example, antiarrhythmic drugs for rate control in those with permanent $\mathrm{AF}$ and aspirin monotherapy for stroke prevention. ${ }^{8}$ Evidence also suggests that deprescribing of NSAIDs may improve outcomes in anticoagulated patients with $\mathrm{AF}^{47}$ The adoption of these and other evidence-based recommendations into practice may be improved by guidelines including a separate discussion and summary of deprescribing advice. Recommendations for managing the overall pharmacotherapy of patients with $\mathrm{AF}$ in the context of potential drug interactions and other common comorbidities including hypertension, heart failure and diabetes may also help minimise adverse outcomes. ${ }^{5758}$

Intervention studies of comprehensive medication review and deprescription of inappropriate pharmacotherapy using shared decision-making are needed to evaluate whether polypharmacy is a modifiable risk factor in patients with $\mathrm{AF}$ or represents a risk marker for adverse outcomes.

\section{Limitations}

Our study has several limitations worthy of consideration. While two of the included studies in our metaanalysis adjusted for multiple confounders, ${ }^{33} 37$ the other had limited adjustment for age, sex and geographical location. ${ }^{32}$ Even extensive adjustment however may not account for all variables which influence prescribing and health outcomes, including frailty, falls history and other unmeasured health variables. However, it is possible that polypharmacy represents a 'risk marker' in individuals with highly prevalent comorbidities and is not in itself responsible for the adverse effects observed. Despite heterogeneity in adjustment, the magnitude of effect of polypharmacy on statistically significant outcomes was similar, lending strength to the conclusion of 
polypharmacy-associated harm. Furthermore, the associated risk demonstrated a dose-dependent increase, with more 'severe' levels of polypharmacy resulting in incrementally greater risk of adverse events. We were, however, unable to determine the appropriateness of the medicines prescribed for each patient which may also be a contributing factor to polypharmacy-related harm. Other unreported factors may also impact on adverse outcomes, including the number of prescribers caring for individuals. This has been shown to be an independent predictor of adverse drug events, ${ }^{1859}$ with each additional specialist conferring a $19 \%$ increase in risk in a multicentre observational study. ${ }^{18}$

Studies included in our meta-analysis are based on polypharmacy at the time of study enrolment, and the duration of polypharmacy during the study is uncertain. Finally, although only three studies were available for meta-analysis, the total number of patients was 33602 with independently adjudicated outcomes, which strengthens the evidence for polypharmacy-associated harm. Our systematic review identified six studies examining this area, which demonstrates the need for future research to further confirm our findings, in addition to interventions designed to reduce the risk of polypharmacy-related adverse events in AF.

\section{CONCLUSIONS}

The growing burden of AF has led to a pressing need to identify ways in which outcomes can be improved in this population. Polypharmacy is common among individuals with $\mathrm{AF}$, and our results demonstrate that it is associated with numerous adverse outcomes. Causal mechanisms underlying this risk are unclear and may be multifactorial, including the use of concomitant high-risk medications, poor adherence or persistence to prescribed regimens, or unclear communication between numerous prescribers, and between prescribers and their patients. Further studies examining deprescription of inappropriate pharmacotherapy in patients with AF are warranted to evaluate whether polypharmacy is a modifiable risk factor.

\section{Acknowledgements The authors thank Professor Philipp Wild, Ms Lisa} Eggebrecht and Drs Jürgen Prochaska and Markus Nagler from the thrombEVAL study team for providing additional data used in this meta-analysis.

Contributors CG and KNH conceived and designed the study. CG and KNH undertook data collection and statistical analysis. CG, KNH, PS, DR and JMH drafted the manuscript. All authors critically revised the manuscript for important content. All authors had access to all data and contributed to the analysis and interpretation of the data.

Funding CG and MEM are supported by Postdoctoral Fellowships from the University of Adelaide. CXW is supported by a Neil Hamilton Fairley Scholarship from the National Health and Medical Research Council (NHMRC) of Australia. RM is supported by a Postdoctoral Fellowship from the NHMRC and by the Leo J Mahar Lectureship from the University of Adelaide. DHL is supported by a Hospital Research Foundation Fellowship and the Robert J Craig Lectureship from the University of Adelaide. PS is supported by a Practitioner Fellowship from the NHMRC and also by the National Heart Foundation of Australia. JMH is supported by a Future Leader Fellowship by the National Heart Foundation of Australia.

Competing interests CXW reports that the University of Adelaide has received lecture, travel and research funding on his behalf from Novartis, Servier, Boehringer Ingelheim and Medtronic. RM reports that the University of Adelaide has received lecture fees and research funding on his behalf from Medtronic and St Jude Medical. PS reports having served on the advisory board of Biosense Webster, Medtronic, St Jude Medical and CathRx. PS reports that the University of Adelaide has received on his behalf lecture and/or consulting fees from Biosense-Webster, Medtronic and St Jude Medical. PS reports that the University of Adelaide has received on his behalf research funding from Medtronic, St Jude Medical, Boston Scientific, Biotronik and LivaNova. JMH reports that the University of Adelaide has received on his behalf lecture and/or consulting fees from Medtronic and Pfizer/ BMS.

Patient consent for publication Not required.

Provenance and peer review Not commissioned; externally peer reviewed.

Data availability statement All data relevant to the study are included in the article or uploaded as supplementary information.

Open access This is an open access article distributed in accordance with the Creative Commons Attribution Non Commercial (CC BY-NC 4.0) license, which permits others to distribute, remix, adapt, build upon this work non-commercially, and license their derivative works on different terms, provided the original work is properly cited, appropriate credit is given, any changes made indicated, and the use is non-commercial. See: http://creativecommons.org/licenses/by-nc/4.0/.

Correction notice This paper has been updated since first published to correct author name 'Prashanthan Sanders'.

ORCID iDs

Rajiv Mahajan http://orcid.org/0000-0003-3375-5568

Jeroen M Hendriks http://orcid.org/0000-0003-4326-9256

\section{REFERENCES}

1 Chen MA. Multimorbidity in older adults with atrial fibrillation. Clin Geriatr Med 2016;32:315-29.

2 Nabauer M, Gerth A, Limbourg T, et al. The registry of the German competence network on atrial fibrillation: patient characteristics and initial management. Europace 2009;11:423-34.

3 Andersson T, Magnuson A, Bryngelsson I-L, et al. All-Cause mortality in 272186 patients hospitalized with incident atrial fibrillation 1995-2008: a Swedish nationwide long-term case-control study. Eur Heart J 2013;34:1061-7.

4 Jani BD, Nicholl BI, McQueenie R, et al. Multimorbidity and comorbidity in atrial fibrillation and effects on survival: findings from UK Biobank cohort. EP Europace 2017:eux322-eux.

5 Whelton PK, Carey RM, Aronow WS, et al. 2017 ACC/AHA/AAPA ABC/ACPM/AGS/APhA/ASH/ASPC/NMA/PCNA guideline for the prevention, detection, evaluation, and management of high blood pressure in adults. J Am Coll Cardiol 2018;71:e127-248.

6 Yancy CW, Jessup M, Bozkurt B, et al. 2017 ACC/AHA/HFSA Focused Update of the 2013 ACCF/AHA Guideline for the Management of Heart Failure. J Am Coll Cardiol 2017;70:776-803.

7 Ponikowski P, Voors AA, Anker SD, et al. 2016 ESC Guidelines for the diagnosis and treatment of acute and chronic heart failure. The Task Force for the diagnosis and treatment of acute and chronic heart failure of the European Society of Cardiology (ESC)Developed with the special contribution of the Heart Failure Association (HFA) of the ESC. Eur Heart J 2016;37:2129-200.

8 Kirchhof P, Benussi S, Kotecha D, et al. 2016 ESC guidelines for the management of atrial fibrillation developed in collaboration with EACTS. Eur Heart J 2016;37:2893-962.

9 January CT, Wann LS, Alpert JS, et al. 2014 AHA/ACC/HRS Guideline for the Management of Patients With Atrial Fibrillation: Executive Summary. J Am Coll Cardiol 2014;64:2246-80.

10 Levine GN, Bates ER, Bittl JA, et al. 2016 ACC/AHA guideline focused update on duration of dual antiplatelet therapy in patients with coronary artery disease: a report of the American College of Cardiology/American heart association Task force on clinical practice guidelines. J Thorac Cardiovasc Surg 2016;152:1243-75.

11 Masnoon N, Shakib S, Kalisch-Ellett L, et al. What is polypharmacy? A systematic review of definitions. BMC Geriatr 2017; 17:230

12 Viktil KK, Blix HS, Moger TA, et al. Polypharmacy as commonly defined is an indicator of limited value in the assessment of drugrelated problems. Br J Clin Pharmacol 2007;63:187-95.

13 Fried TR, O'Leary J, Towle V, et al. Health outcomes associated with polypharmacy in community-dwelling older adults: a systematic review. J Am Geriatr Soc 2014;62:2261-72. 
14 Nishtala PS, Narayan SW, Wang T, et al. Associations of drug burden index with falls, general practitioner visits, and mortality in older people. Pharmacoepidemiol Drug Saf 2014;23:753-8.

15 Bonaga B, Sánchez-Jurado PM, Martínez-Reig M, et al. Frailty, Polypharmacy, and Health Outcomes in Older Adults: The Frailty and Dependence in Albacete Study. J Am Med Dir Assoc 2018;19:46-52.

16 Richardson K, Ananou A, Lafortune L, et al. Variation over time in the association between polypharmacy and mortality in the older population. Drugs Aging 2011;28:547-60.

17 Beer C, Hyde Z, Almeida OP, et al. Quality use of medicines and health outcomes among a cohort of community dwelling older men: an observational study. Br J Clin Pharmacol 2011;71:592-9.

18 Calderón-Larrañaga A, Poblador-Plou B, González-Rubio F, et al. Multimorbidity, polypharmacy, referrals, and adverse drug events: are we doing things well? Br J Gen Pract 2012;62:e821-6.

19 Alhawassi TM, Krass I, Bajorek BV, et al. A systematic review of the prevalence and risk factors for adverse drug reactions in the elderly in the acute care setting. Clin Interv Aging 2014;9:2079-86.

20 Huang ES, Karter AJ, Danielson KK, et al. The association between the number of prescription medications and incident falls in a multiethnic population of adult type- 2 diabetes patients: the diabetes and aging study. J Gen Intern Med 2010;25:141-6.

21 Zia A, Kamaruzzaman SB, Tan MP. Polypharmacy and falls in older people: balancing evidence-based medicine against falls risk. Postgrad Med 2015;127:330-7.

22 Sganga F, Landi F, Ruggiero C, et al. Polypharmacy and health outcomes among older adults discharged from Hospital: results from the crime study. Geriatr Gerontol Int 2015;15:141-6.

23 Fabbietti P, Di Stefano G, Moresi R, et al. Impact of potentially inappropriate medications and polypharmacy on 3-month readmission among older patients discharged from acute care Hospital: a prospective study. Aging Clin Exp Res 2018;30:977-84.

24 Jyrkkä J, Enlund H, Korhonen MJ, et al. Patterns of drug use and factors associated with polypharmacy and excessive polypharmacy in elderly persons. Drugs Aging 2009;26:493-503.

25 Montiel-Luque A, Núñez-Montenegro AJ, Martín-Aurioles E, et al. Medication-Related factors associated with health-related quality of life in patients older than 65 years with polypharmacy. PLoS One 2017;12:e0171320.

26 Chiatti C, Bustacchini S, Furneri G, et al. The economic burden of inappropriate drug prescribing, lack of adherence and compliance, adverse drug events in older people. Drug Saf 2012;35:73-87.

27 Sorensen L, Stokes JA, Purdie DM, et al. Medication management at home: medication-related risk factors associated with poor health outcomes. Age Ageing 2005;34:626-32.

28 Proietti M, Raparelli V, Olshansky B, et al. Polypharmacy and major adverse events in atrial fibrillation: observations from the Affirm trial. Clin Res Cardiol 2016;105:412-20.

29 Wang Y, Singh S, Bajorek B. Old age, high risk medication, polypharmacy: a trilogy of risks in older patients with atrial fibrillation. Pharm Pract 2016;14:706.

30 Locquet M, Honvo G, Rabenda V, et al. Adverse health events related to self-medication practices among elderly: a systematic review. Drugs Aging 2017;34:359-65.

31 Nobili A, Marengoni A, Tettamanti M, et al. Association between clusters of diseases and polypharmacy in hospitalized elderly patients: results from the REPOSI study. Eur J Intern Med 2011;22:597-602.

32 Jaspers Focks J, Brouwer MA, Wojdyla DM, et al. Polypharmacy and effects of apixaban versus warfarin in patients with atrial fibrillation: post hoc analysis of the ARISTOTLE trial. BMJ 2016;353:i2868.

33 Piccini JP, Hellkamp AS, Washam JB, et al. Polypharmacy and the efficacy and safety of rivaroxaban versus warfarin in the prevention of stroke in patients with nonvalvular atrial fibrillation. Circulation 2016;133:352-60.

34 Moher D, Liberati A, Tetzlaff J, et al. Preferred reporting items for systematic reviews and meta-analyses: the PRISMA statement. BMJ 2009;339:b2535.

35 Schulman S, Kearon C, Subcommittee on Control of Anticoagulation of the Scientific and Standardization Committee of the International Society on Thrombosis and Haemostasis. Definition of major bleeding in clinical investigations of antihemostatic medicinal products in non-surgical patients. J Thromb Haemost 2005;3:692-4.

36 Hayden JA, van der Windt DA, Cartwright JL, et al. Assessing bias in studies of prognostic factors. Ann Intern Med 2013;158:280-6.
37 Eggebrecht L, Nagler M, Göbel S, et al. Relevance of polypharmacy for clinical outcome in patients receiving vitamin $\mathrm{K}$ antagonists. J Am Geriatr Soc 2019;67:463-70.

38 Roalfe AK, Bryant TL, Davies MH, et al. A cross-sectional study of quality of life in an elderly population (75 years and over) with atrial fibrillation: secondary analysis of data from the Birmingham atrial fibrillation treatment of the aged study. Europace 2012;14:1420-7.

39 McAvay G, Allore HG, Cohen AB, et al. Guideline-Recommended medications and physical function in older adults with multiple chronic conditions. J Am Geriatr Soc 2017;65:2619-26.

40 Prochaska JH, Coldewey M, Göbel S, et al. Evaluation of oral anticoagulation therapy: rationale and design of the thrombEVAL study programme. Eur J Prev Cardiol 2015;22:622-8.

41 Mastromarino V, Casenghi M, Testa M, et al. Polypharmacy in heart failure patients. Curr Heart Fail Rep 2014;11:212-9.

42 Wong CY, Chaudhry SI, Desai MM, et al. Trends in comorbidity, disability, and polypharmacy in heart failure. Am J Med 2011;124:136-43.

43 Chapman RHet al. Predictors of adherence with antihypertensive and lipid-lowering therapy. Arch Intern Med 2005;165:1147-52.

44 Gastelurrutia P, Benrimoj SI, Espejo J, et al. Negative clinical outcomes associated with drug-related problems in heart failure (HF) outpatients: impact of a pharmacist in a multidisciplinary HF clinic. $J$ Card Fail 2011;17:217-23.

45 Borne RT, O'Donnell C, Turakhia MP, et al. Adherence and outcomes to direct oral anticoagulants among patients with atrial fibrillation: findings from the Veterans health administration. BMC Cardiovasc Disord 2017:17:236.

46 Chang S-H, Chou I-J, Yeh Y-H, et al. Association between use of Non-Vitamin $\mathrm{K}$ oral anticoagulants with and without concurrent medications and risk of major bleeding in nonvalvular atrial fibrillation. JAMA 2017;318:1250-9.

47 Kent AP, Brueckmann M, Fraessdorf M, et al. Concomitant oral anticoagulant and nonsteroidal anti-inflammatory drug therapy in patients with atrial fibrillation. J Am Coll Cardiol 2018;72:255-67.

48 Goldberg RM, Mabee J, Chan L, et al. Drug-Drug and drug-disease interactions in the ED: analysis of a high-risk population. Am J Emerg Med 1996;14:447-50.

49 Dumbreck S, Flynn A, Nairn M, et al. Drug-disease and drug-drug interactions: systematic examination of recommendations in $12 \mathrm{UK}$ national clinical guidelines. BMJ 2015;350:h949.

50 Skov J, Bladbjerg E-M, Sidelmann J, et al. Plenty of pills: polypharmacy prevails in patients of a Danish anticoagulant clinic. Eur J Clin Pharmacol 2011;67:1169-74

51 Wong CX, Brooks AG, Leong DP, et al. The increasing burden of atrial fibrillation compared with heart failure and myocardia infarction: a 15-year study of all hospitalizations in Australia. Archives of Internal Medicine 2012;172:739-41.

52 Jackson SL, Tong X, Yin X, et al. Emergency department, hospita inpatient, and mortality burden of atrial fibrillation in the United States, 2006 to 2014. Am J Cardiol 2017;120:1966-73.

53 Hung C-Y, T-J W, Wang K-Y, et al. Falls and atrial fibrillation in elderly patients. Acta Cardiol Sin 2013;29:436-43.

54 Wong CX, Gan SW, Lee SW, et al. Atrial fibrillation and risk of hip fracture: a population-based analysis of 113,600 individuals. Int $J$ Cardiol 2017;243:229-32

55 Rao MP, Vinereanu D, Wojdyla DM, et al. Clinical outcomes and history of fall in patients with atrial fibrillation treated with oral anticoagulation: insights from the ARISTOTLE trial. Am J Med 2018:131:269-75.

56 Reeve E, Thompson W, Farrell B. Deprescribing: a narrative review of the evidence and practical recommendations for recognizing opportunities and taking action. Eur J Intern Med 2017;38:3-11.

57 Marengoni A, Onder G, Guidelines OG. Guidelines, polypharmacy, and drug-drug interactions in patients with multimorbidity. BMJ 2015;350:h1059.

58 Tinetti ME, Bogardus ST, Agostini JV. Potential pitfalls of diseasespecific guidelines for patients with multiple conditions. $N$ Engl $J$ Med 2004;351:2870-4

59 Green JL, Hawley JN, Rask KJ. Is the number of prescribing physicians an independent risk factor for adverse drug events in an elderly outpatient population? Am J Geriatr Pharmacother 2007;5:31-9. 